http://jmscr.igmpublication.org/home/ ISSN (e)-2347-176x ISSN (p) 2455-0450

crossref DOI: https://dx.doi.org/10.18535/jmscr/v8i2.106

Journal Of Medical Science And Clinical Research

\title{
Arthroscopic Assisted Internal Fixation (AAIF) of Tibial Plateau Fractures; A Novel Technique
}

\author{
Authors \\ Ansarul Haq Lone ${ }^{1}$, Dar Ghulam Nabi ${ }^{2}$, Mohammad Mussa ${ }^{3}$ \\ ${ }^{1}$ MS Orthopaedics, Lecturer Postgraduate Department of Orthopedics GMC Srinagar \\ ${ }^{2}$ MS Ortho, Assistant Professor Department of Orthopedics GMC Srinagar \\ ${ }^{3}$ MS Ortho, Assistant Professor of Orthopedics GMC Srinagar
}

\begin{abstract}
Introduction: The difficulty in achieving precise reduction using conservative methods and the higher morbidity associated with traditional surgical methods have led to the development of semi invasive techniques. The treatment of tibial plateau fractures with AAIF is one method that is associated with lower morbidity, less extensive surgical dissection. Furthermore, arthroscopy allows the surgeon to diagnose and treat concomitant intra-articular injuries.

Methods and Materials: This study consisted of 25 patients with closed fractures of tibial plateau in adults of both sexes and was conducted in the post-graduate department of orthopaedics Bone and Joint Surgery Hospital, Government Medical College Srinagar from September 2011 to October 201. After thorough preoperative work-up AAIF was done in all 25 patients and in some patients bone grafting was done elevating the depressed articular fragment in these cases fixation was done using 2 or 3 hole proximal tibial locking compression plates.

Observations and Results: In our study 14 patients had type II (split depression of lateral condyle) tibial plateau fractures, 7 patients had type I fractures. 2 patients each with Type III and type IV tibial plateau fractures. Most common type of intra-articular injuries in our study was meniscal injuries comprising of $40 \%$ of all cases. Lateral meniscal injuries were more common than medial meniscal injuries, because lateral condyle fractures were more than medial condyle fractures.

Discussion: Review of the literature suggests AAIF to be equal to or better than open reduction internal fixation (ORIF) in achieving anatomical reduction. In the study of H. Kiefer et al (2001) of a series of 31 fractures, 25 showed anatomical reduction at a mean of 25 months. F. Van Glabbeek and van Riet (2002) were unable to arthroscopically reduce only 1 of 20 split/depression fractures.

Conclusion: AAIF is a novel technique in the treatment of properly selected cases of tibial plateau fractures because of diagnosis and treatment of associated intra-articular soft tissue injuries and visualization of chondral surface reduction.

Keywords: Arthroscopy, Tibial Plateau, Soft-tissue injuries.
\end{abstract}

\section{Introduction}

Tibial plateau fractures make up $1 \%$ of all fractures and $8 \%$ of fractures in elderly. Lateral tibial plateau fractures account for 55 to $70 \%$ of cases. Medial tibial plateau fractures account for $10-25 \% .10$ to $30 \%$ are bicondylar fractures. 1 to $3 \%$ are compound fractures ${ }^{(22,31,39,59,62)}$. Traditional surgical methods achieve satisfactory 
results in $70-80 \%$ of cases however, these methods have a high incidence of complications including loss of reduction, infection, and septic arthritis. ${ }^{62}$ The goals of treatment are restoration of normal alignment, joint congruity, joint stabilization and, ultimately, the prevention of degenerative osteoarthritis. ${ }^{19,20,25,31,59}$

There have been many options for the treatment of tibial plateau fractures in orthopaedic literature including conservative treatment, external fixation, open reduction-internal fixation (ORIF) and arthroscopically assisted osteosynthesis. ${ }^{9}$ The ultimate goal of the intra-articular fracture treatment should be the precise restoration of the joint surface and stable fixation to allow immediate Postoperative non-weight-bearing exercises. ${ }^{9,20}$ The difficulty in achieving precise reduction using conservative methods and the higher morbidity associated with traditional surgical methods have led to the development of semi invasive techniques. $^{20,62}$ The treatment of tibial plateau fractures with AAIF is one method that is associated with lower morbidity, less extensive surgical dissection. ${ }^{4,18,20,44,}$ Furthermore, arthroscopy allows the surgeon to diagnose and treat concomitant intra-articular injuries. ${ }^{9,18,20}$

Indications for surgical management of tibial plateau fractures has been inconsistent with limits of acceptable articular displacement ranging from 2 to $10 \mathrm{~mm} .{ }^{7,38,44}$ Residual tilt of the tibial plateau and varus or valgus malalignment have been associated with higher risk of arthrosis. ${ }^{7}$ Biomechanical studies on articular step-off show that a 6-mm step-off of the lateral plateau produces 7.6 degrees of increased valgus and a $208 \%$ increase in contact pressure. ${ }^{7,39,44}$ Holzach $(1994)^{27}$ has recommended surgical treatment of ski-related plateau fractures with $2 \mathrm{~mm}$ or more of displacement. Honkonen(1994) ${ }^{28}$ evaluated outcomes in 131 tibial plateau fractures and recommended surgical management for more than 5 degrees of valgus malalignment, more than 3 $\mathrm{mm}$ of articular step-off and more than $5 \mathrm{~mm}$ of condylar widening. In actuality, multiple factors likely contribute to long-term outcome, and consideration should be given to fracture type, presence of laxity on examination, location of articular displacement (central vs submeniscal) associated soft tissue injuries, and patient's factors such as age, activity level, and comorbidities. $^{2,38,44}$

The goal of the treatment is to obtain a stable joint permitting early range of motion for cartilage nourishment and preservation to prevent post traumatic osteoarthritis. ${ }^{42}$ The advantages of arthroscopic management of tibial plateau fractures are ar, $^{(2,9,18,20,22,23,25,31,38,44,55,62)}$

1) Direct visualization of chondral surface reduction

2) Accurate fracture reduction

3) Anatomical restoration of joint surface

4) Reduced morbidity in comparison with arthrotomy

5) Diagnosis and treatment of associated meniscal and ligamentous injuries

6) Thorough joint lavage

7) Removal of loose fragments

8) Early post op recovery.

Methods and Materials: This study consisted of 25 patients with closed fractures of tibial plateau in adults of both sexes and was conducted in the post-graduate department of orthopaedics Bone and Joint Surgery Hospital, Government Medical College Srinagar from September 2011 to October 2013. As tibial plateau fractures are rare, $1 \%$ of all fractures and more complex tibial plateau fractures type V and types VI were excluded from the study ${ }^{2,23}$ so only 25 cases were included which was consistent with number of patients studied by other authors which in most cases was less than 25. Final follow up was done at 6 months. Patients aged more than 18 years of either sex with closed tibial plateau fracture Type I to type IV according to Schatzker classification were included in the study. The patient were operated in supine position in all patients surgery was conducted under spinal anesthesia. ${ }^{20} \mathrm{~A}$ pneumatic tourniquet was used in all cases with the affected leg off of the end of table. ${ }^{31,38,55,62}$ Portal sites were marked before doing arthroscopy. 
Arthroscopy knee was done via standard anteromedial and antero-lateral portals. ${ }^{35,55,62}$

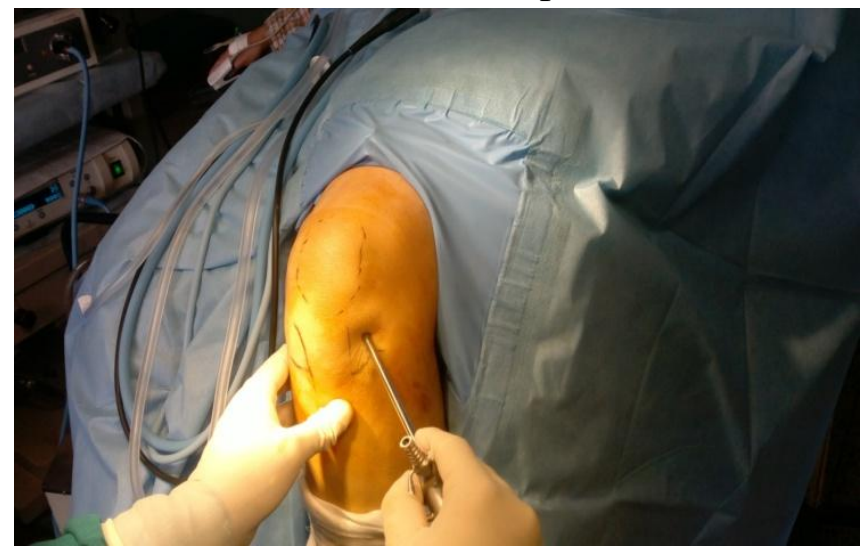

Thorough joint lavage was done to remove blood clots, fragments of loose bone and articular cartilage. $^{31,35,38,44,55,62}$

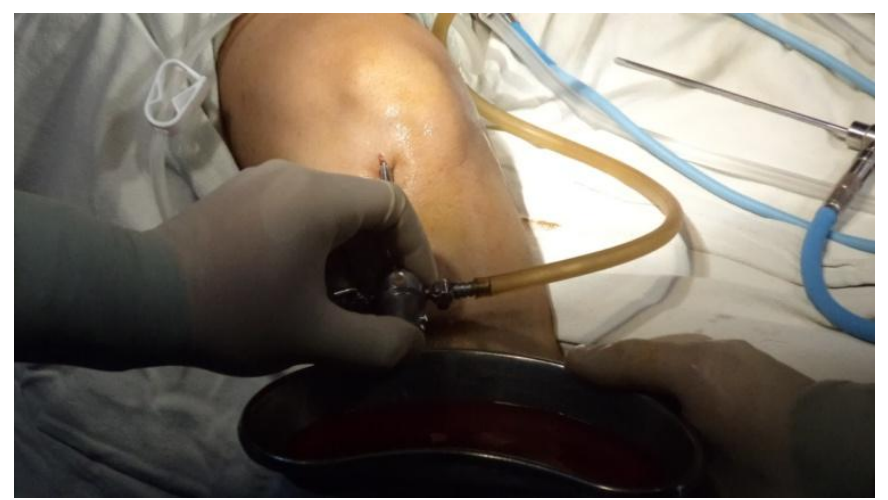

In all cases inflow pressure was kept minimum to reduce risk of fluid extravasation and increase in compartment pressure. ${ }^{31,44}$

The joint was carefully examined for associated injuries, including cruciate ligaments and menisci. $9,31,38,62$

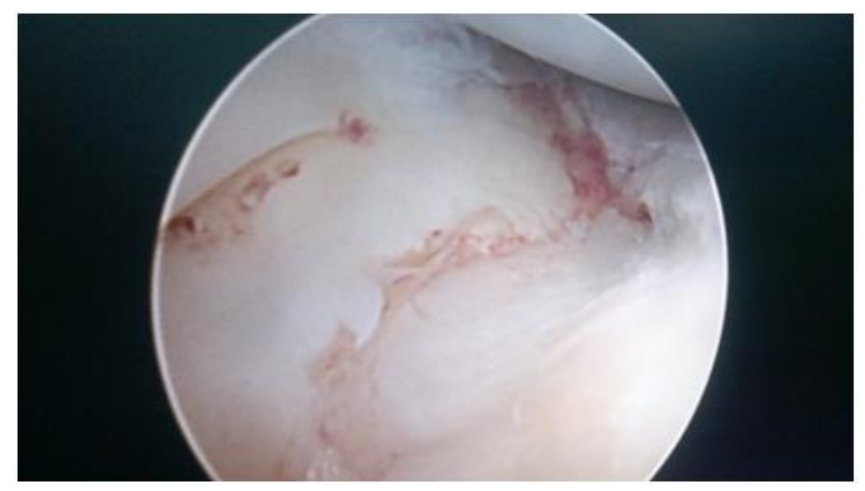

A probe was inserted through one of the portals to examine the fracture site. Debridement of the fracture site was performed. ${ }^{31,38}$ In cases were fracture visualization was impaired by overlying meniscus retraction of meniscus was done by hooked arthroscopic probe. ${ }^{44}$

In case of tibial plateau with articular depression elevation of articular surface was done by approaching the lateral tibial plateau through inverted L shaped incision. ${ }^{7,31,55}$ Horizontal limb of the incision was extended from the tibial tuberosity to Gerdy' tubercle and vertical limb was extended lateral to the tibial crest just below the fracture line, muscle origin was reflected laterally until fracture was exposed. ${ }^{7}$ Lateral fragment was retracted to give access to the central part of the tibial condyle, exposing the depressed articular surface and cancellous bone of the central depression. ${ }^{7}$ In some cases cortical window was made below the area of depression and elevation of the depressed fragment was done using bone punch. ${ }^{18,25,31,38,62}$
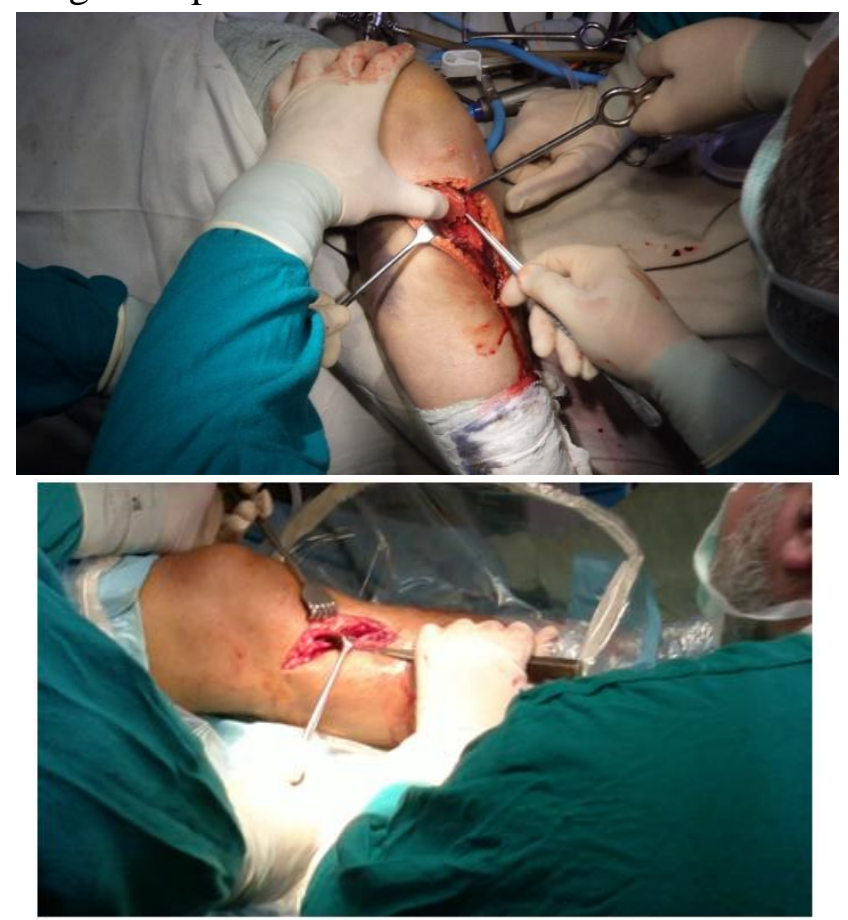

Bone punch was inserted beneath the depressed articular fragments or through the cortical window and by slow and meticulous pressure elevation of the articular fragment and compressed cancellous bone was done. $^{22,31,38,44}$ The resultant bone defect was filled by the bone graft taken from the ipsilateral iliac crest. ${ }^{2,18,22,31,38}$ As the fragment were elevated and reduced temporarily fixation was done with $\mathrm{k}$ wires. Reduction was confirmed by arthroscopic examination. ${ }^{22,31,38,55,62}$ 


\section{JMSCR Vol||08||Issue||02||Page 603-612||February}

After reduction fracture was stabilised using proximal tibial locking compression plate. ${ }^{10,44}$ Plate was precisely fitted with tibial condyles. Plate was secured to the condyle with appropriate locking cancellous screws of sufficient length to engage the opposite cortex. Locking screws of $4.5 \mathrm{~mm}$ were used to attach the plate to the shaft of tibia. $^{7,10}$

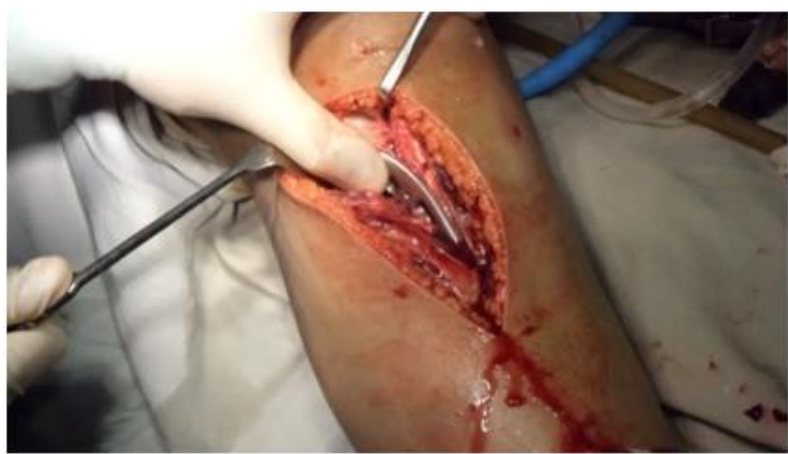

In case of Split tibial plateau fractures Type I and Type IVa with little or no comminution and little central depression reduction was done using joy stick technique. ${ }^{9,18,22,31,38,44,62}$ A kirschner wire or Steinman' pin was introduced into fracture fragment to facilitate manipulation under fluoroscopic guidance. When an adequate reduction was achieved fixation was done using 6.5 cannulated screws of appropriate length. ${ }^{9,18,22,38}$ In case of greater comminution and osteoporotic bones either cannulated screws were used along with washer or proximal tibial locking plate was used through small incision over fracture site. ${ }^{22,31,44}$

Pre-reduction arthroscopic view of split tibial condyle fracture

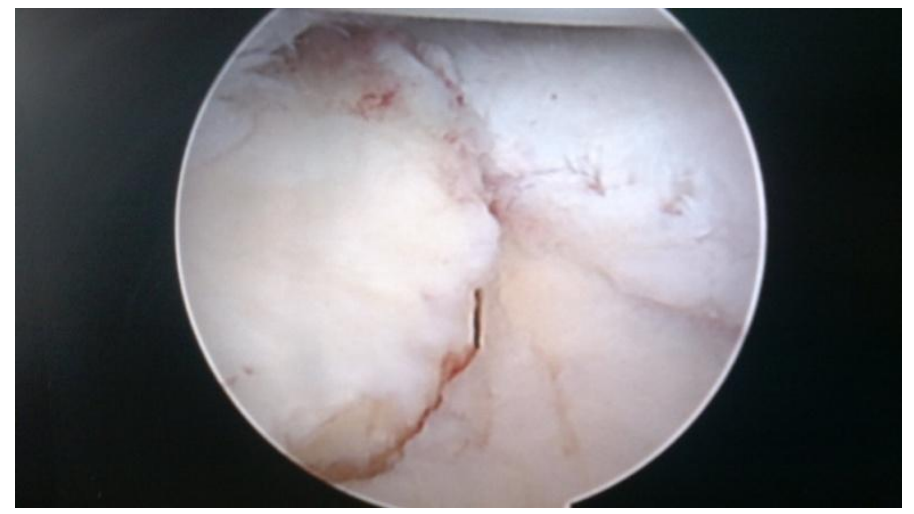

Arthroscopic view during reduction with joy stick technique

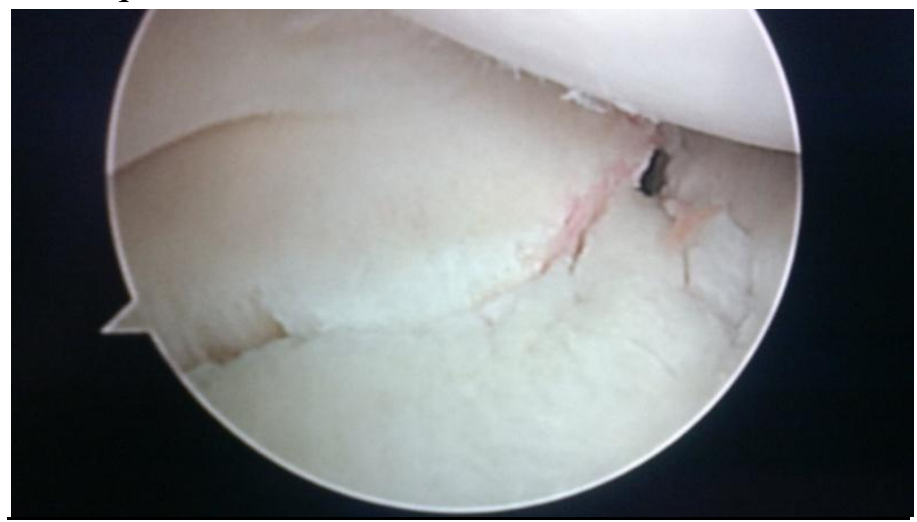

After reduction arthroscopic view

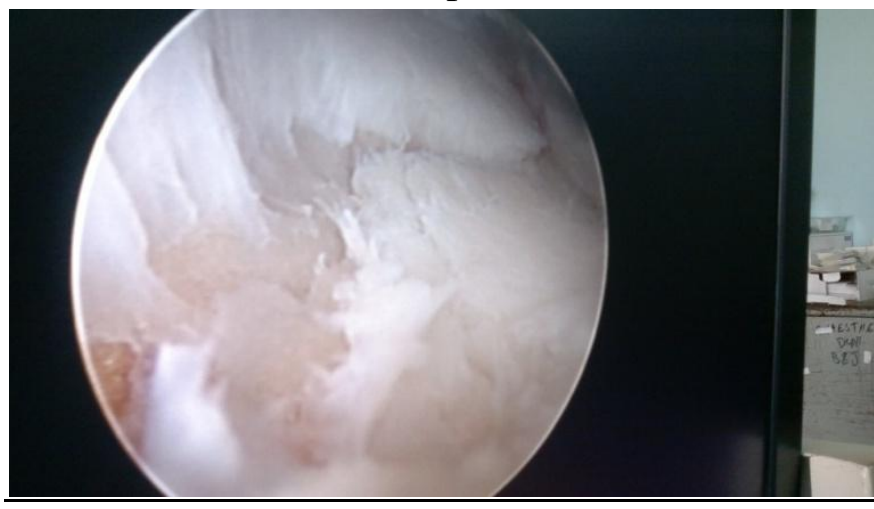

After fixation of fracture arthroscopic examination was done to confirm the reduction of articular surface, and in patients with meniscal injury partial meniscectomy was done., ${ }^{9,18,22,38}$ Touniquet was released. Hemostasis was achieved. Wound closure done.

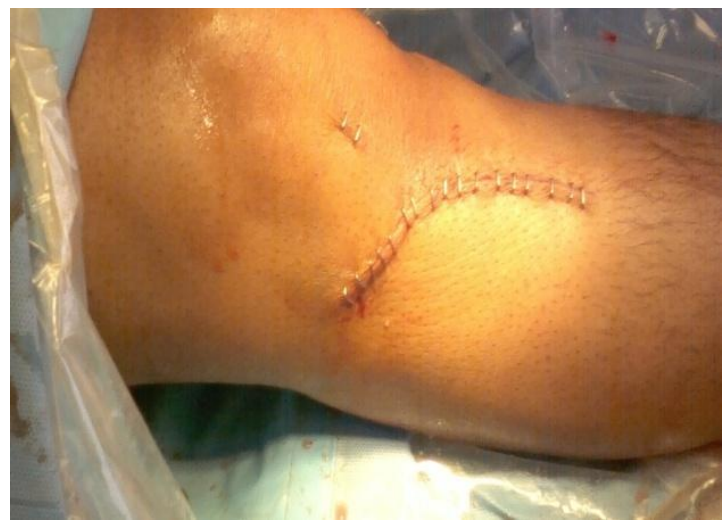

Crutch walking with non weight bearing was allowed as soon as pain was relieved and anesthesia effects were over usually on first post operative day. ${ }^{18,23,31,38}$ Active ROM exercises was started $2^{\text {nd }}$ post-operative day onwards with goals of $0-90$ deg. at 2 wks and full range of motion at 
6wks. ${ }^{9,18,22,31,38}$ Partial weight bearing was allowed at 9-12 weeks and full weight at 13-16 weeks depending upon clinical and radiological assessment of fracture heeling and type of fracture and any other complication. ${ }^{2,22,23,31,58,62}$ Final assessment was done after 6 months and patients were assessed clinically by Rasmussen grading system. ${ }^{(9,18,20,37,55,62)}$.

Observations and Results: The patients in our study ranged in age from 21-57 years of age with mean age of 39.28 years. Average age for males was 34.92 years and average age for females was 43.61 years. Right limb was involved in $10(40 \%)$ of cases where as left limb was involved in $15(60 \%)$ of cases. Left side was involved more than right side. In our study 14 patients had type II (split depression of lateral condyle) tibial plateau fractures, 7 patients had type I fractures. 2 patients each with Type III and type IV tibial plateau fractures. Most common type of intra-articular injuries in our study was meniscal injuries comprising of $40 \%$ of all cases. Lateral meniscal injuries were more common than medial meniscal injuries, because lateral condyle fractures were more than medial condyle fractures. The reason for less no. of cruciate and collateral ligament injuries in our study was exclusion of high energy type V and type VI tibial plateau fractures. Plate was used in all those cases were elevation of depressed articular surface and bone grafting was done. In our study average partial weight bearing time was 10.68 weeks and ranged from 9-12weeks. In our study average time to full weight bearing was 15.84weeks with range of 15-18weeks. Average union time in our series was 16.48 weeks and ranged from 15-20 weeks. Rasmussen score in our series ranged from 19 to 30 with mean score of 27.5. Over all 21 out of 25 patients showed excellent results, three patients with good and one patient with fair results. There was no case with poor results. All fractures united and most of patients 21 out of 25 returned to their pre injury status.

\section{Case No. 12}

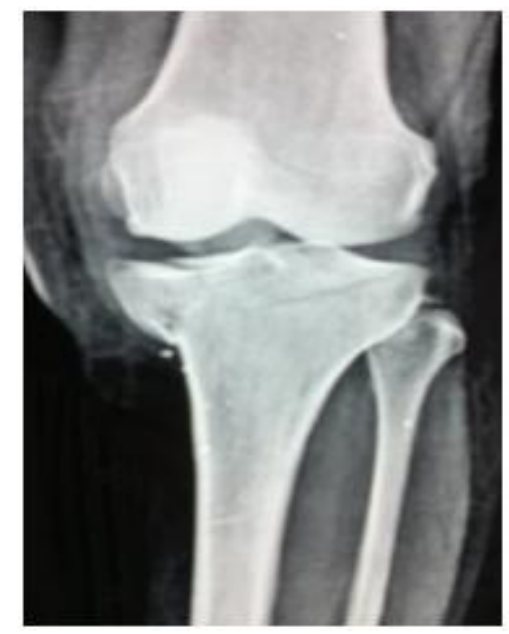

Pre-operative AP View

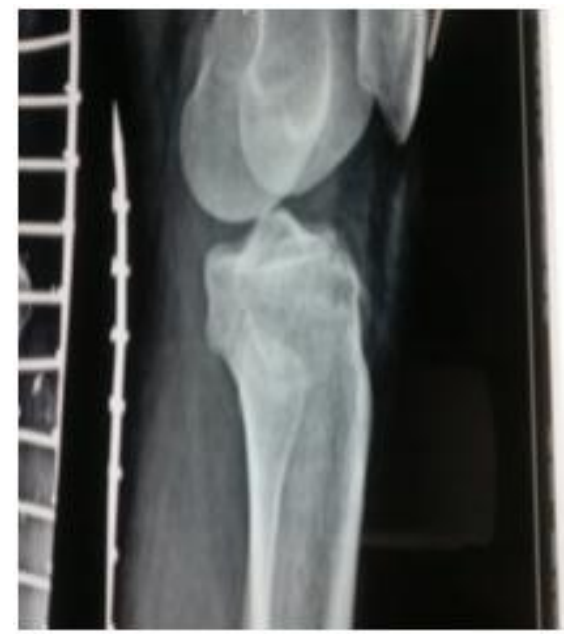

Pre-operative Lateral View

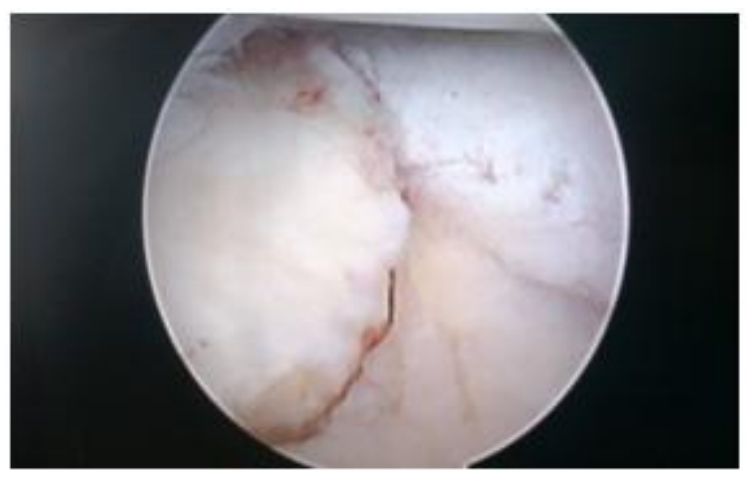

Pre reduction Arthroscopic picture

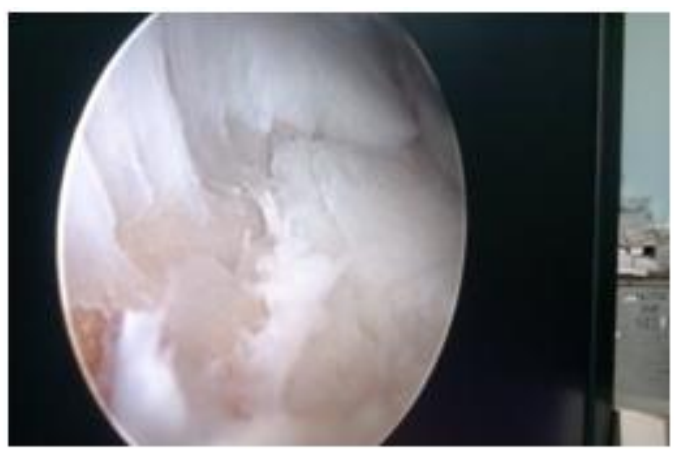

Post reduction Arthroscopic picture 


\begin{tabular}{|l|l|}
\hline JMSCR Vol||08||Issue ||02||Page 603-612||February & 2020 \\
\hline
\end{tabular}

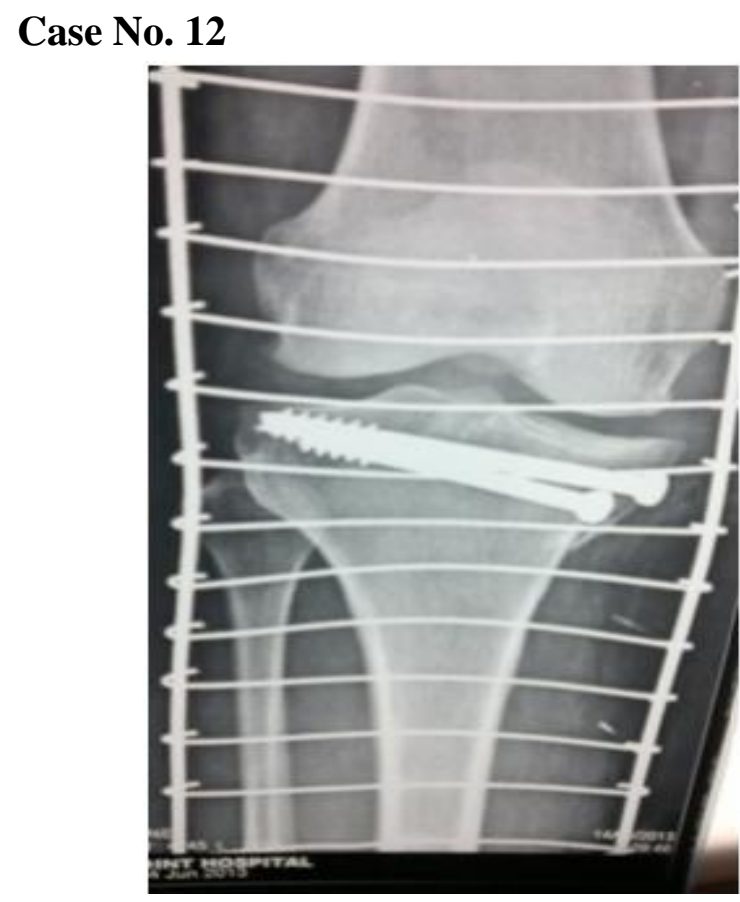

Post-operative AP view

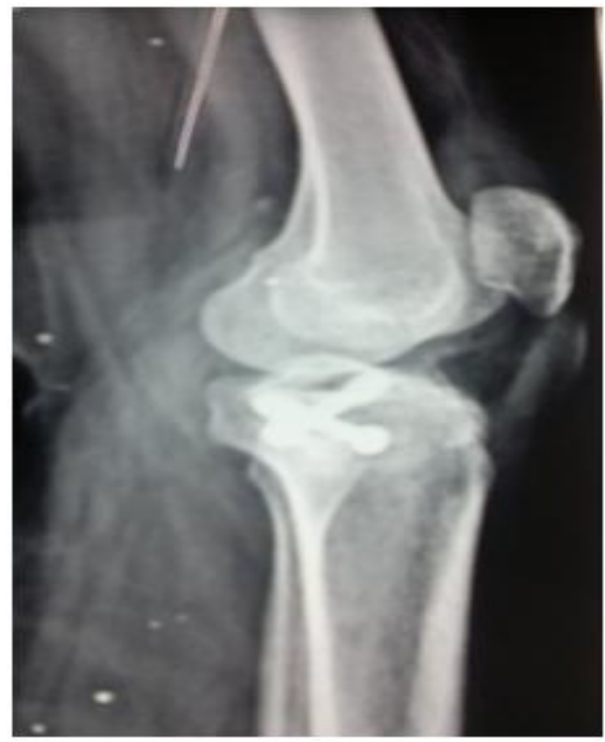

Post-op Lateral View

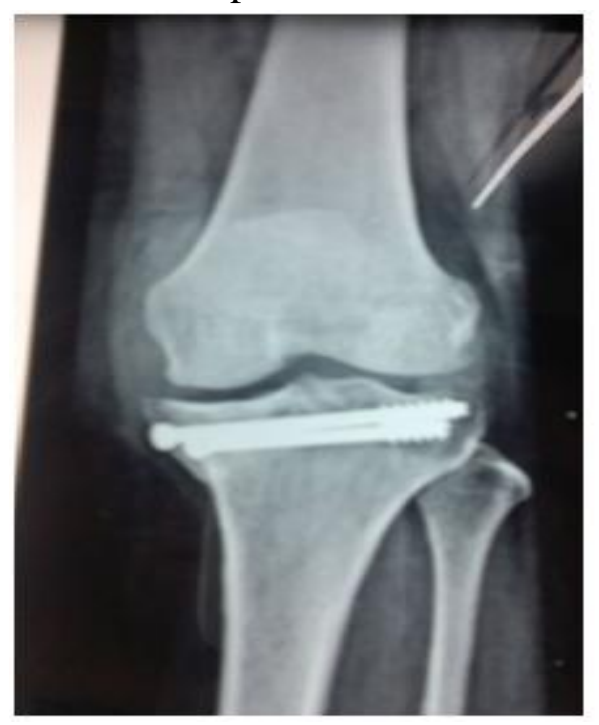

Final follow Up AP view

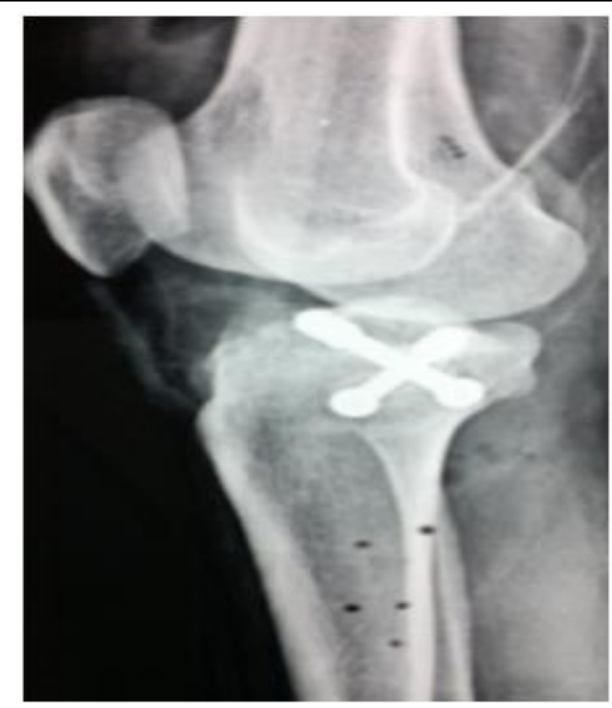

Final Follow-up Lateral View

Case No. 12

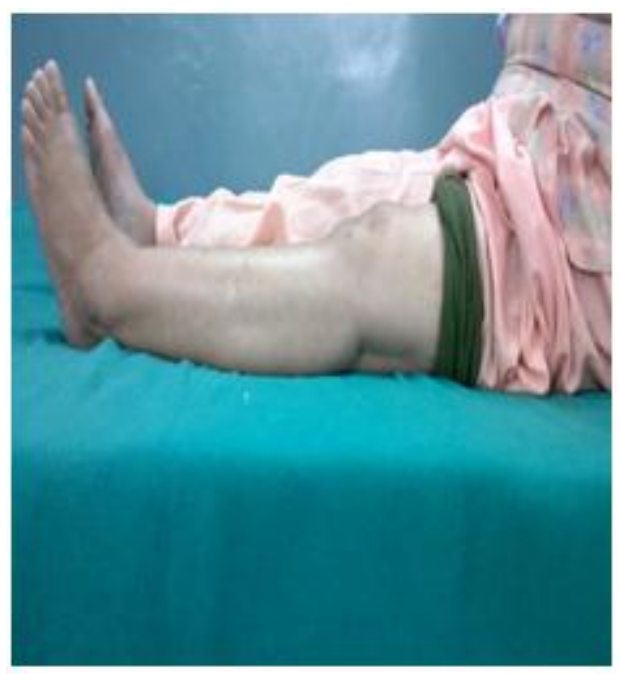

No extension Lag

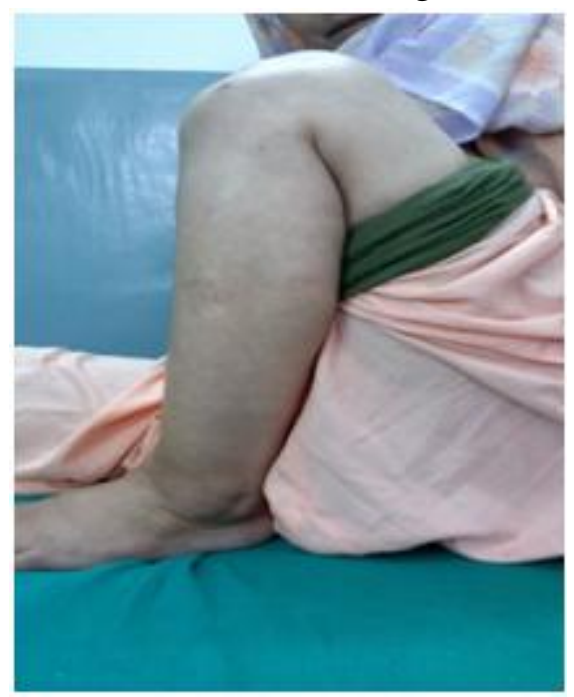

Full ROM 


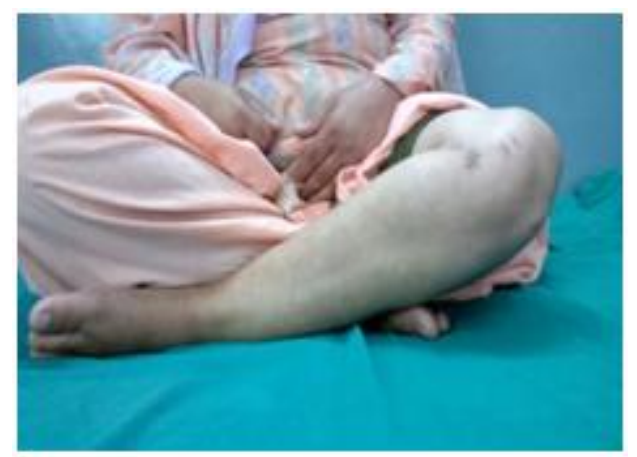

Able to sit cross legged

\section{Discussion}

Gardner $(2006)^{21}$ et al found that soft tissue injury could be predicted based on plain radiographic findings. Articular depression of more than $6 \mathrm{~mm}$ and widening of more than $5 \mathrm{~mm}$ were associated with lateral meniscal tear in $83 \%$ (vs $50 \%$ for less displacement) and more than $8 \mathrm{~mm}$ was associated with increased risk of medial meniscal tear $(53 \%$ $78 \%$ ). Review of the literature suggests AAIF to be equal to or better than open reduction internal fixation (ORIF) in achieving anatomical reduction. In the study of Bernfeld (1996) ${ }^{5}$ et al of a small series of 9 fractures, all reductions remained anatomic at a mean follow-up of 10 months. Fowble et al $(1993)^{17}$ found all of their 12 ARIF patients remained anatomic versus only 6 of 11 for the ORIF group. In the study of H. Kiefer et $\operatorname{al}(2001)^{26}$ of a series of 31 fractures, 25 showed anatomical reduction at a mean of 25 months. F. Van Glabbeek and van Riet (2002) ${ }^{18}$ were unable to arthroscopically reduce only 1 of 20 split/depression fractures. T. Ohdera and Tokunaga $(2003)^{56}$ reported 16 of 19 type II and III fractures were able to be anatomically reduced via ARIF. T. Gill and Moezzi ${ }^{55}$ were able to correct articular depression from an average of 7.7 to $0.8 \mathrm{~mm}$ in 25 patients. Arthroscopy holds advantages in patient cosmesis and, more importantly, soft tissue handling. Less iatrogenic soft tissue injury may reduce intra-articular scarring, thus improving recovery of range of motion. Wound healing and risk of infection may be improved for higher energy fractures, and postoperative pain may be less. Some of these factors have been examined in the literature. Even as early as 1985 , Jennings ${ }^{32}$ noted more rapid recovery, with earlier return of knee motion and reduced pain in 21 patients. T.Ohdera and Tokunaga $(2003)^{56}$ found easier and faster rehabilitation, with time to recovery of 120 degrees of knee flexion 4.6 versus 9.1 weeks for ORIF.

\section{Conclusion}

Arthroscopic assisted reduction and fixation is reliable safe attractive, and excellent option in the treatment of properly selected cases of tibial plateau fractures because of. Diagnosis and treatment of associated intra-articular soft tissue injuries. Visualization of chondral surface reduction. Thorough joint irrigation. Removal of loose fragments. Accurate fracture reduction with limited soft tissue dissection. Decreased risk of knee stiffness and more rapid recovery.

\section{Bibliography}

1. Abdulrahman Khalid Almisfer et al: Closed reduction and percutaneous fixation of non-osteoporotic tibial plateau fractures. Kuwait Medical Journal 2004; 36:15-18.

2. Ali Al-Mukaimi et al: Arthroscopically assisted reduction and treatment of tibial plateau fractures. Kuwait Medical Journal 2005; 37(4): 263-266

3. Andrew Furey et al: Treatment of tibial fractures. Current opinion in orthopedics 2007; 18:49-53.

4. Andre Weimann et al: Minimally invasive reconstruction of lateral tibial plateau fractures using the Jail technique, a biomechanical study. BMC musculoskeletal disorders 2013;14:120

5. Bernfeld $M$ et al: Arthroscopic management for unselected tibial plateau fractures. Arthroscopy 1996; 12:598-602.

6. Brown Ga: Cast braces treatment of plateau and bicondylar fractures of the proximal tibia. Clin Orthop Relat Res Sep1976;119:184-93 
7. Campell's Operative Orthopaedics. $11^{\text {th }}$ edition; vol. 3: 3146-3161

8. Carlos A et al: Arthroscopic management of tibial plateau fractures. The journal of arthroscopic and related surgery 1993;9 (4)467-471.

9. Cemil Kayali et al: Arthroscopic assisted percutaneous osteosynthesis of lateral tibial plateau fractures. Can J surg, vol.51, No.5, october2008.

10. Chen Bin et al: Clinical outcomes of tibial plateau fracture (Schatzker I, II) treated with arthroscopy-assisted management and locked by LCP. Orthopaedic Journal of china 2009 vol. 17 No. 6 pp. 401-403

11. Cole, Peter A. et al: Treatment of proximal tibia fractures using the Less Invasive Stabilization System: surgical experience and early clinical results in 77 fractures. Journal of orthopaedic trauma: September 2004 - volume 18 - issue 8 - pp 528-535.

12. C.Thomas Vangness Jr et al: Arthroscopy of meniscal injuries with tibial plateau fractures. Bone And Joint Surg1994:76;488-90

13. Daniel K. H. Yip: Modified arthroscopic suture fixation of displaced tibial eminence fractures using a suture loop transporter. The Journal of Arthroscopic and Related Surgery, vol 17; 2001: pp 101-106.

14. Decoster Ta et al: Cast brace treatment of proximal tibia fractures. A ten-year followup study. Clin orthop relat res. 1988 Jun (231):196-204.

15. Drennan Db: Treatment of tibial plateau fractures by closed reduction and spica cast. Journal of Bone Joint Surg (Am). 1979; 61(7):989-95.

16. Duan Xiao-Jun et Al: Arthroscopic assisted treatment for shatzker type I to type IV tibial plateau fractures. Chinese Journal of Arthroscopy 2008:11(5):288292.

17. Fowble CD, Zimmer JW et al: The role of arthroscopy in the assessment and treatment of tibial plateau fractures. Arthroscopy 1993;9:584-90

18. F.Van Glabbeek et al: arthroscopically assisted reduction and internal fixation of tibial plateau fractures: report of twenty cases. Acta Orthopedic Belgica; Vol. 68-32002)

19. Fred J. Mcglynn, Richard B Caspari, Terry L. Whipple: the role of arthroscopy in the treatment of tibial plateau fractures: (The Lowa Orthopaedic Journal;1985vol-6:107)

20. Francesco Pogliacomi et al: combined arthroscopic and radioscopic management of tibial plateau fractures: report of 18 clinical cases. Acta Biomed 2005; 76; 107 114)

21. Garden MJ, et al. Prediction of soft tissue injuries in schatzker II tibial plateau fractures based on measurements of plain radiographs. J trauma 2006;60:319-323

22. G. Burdin: Arthroscopic management of tibial plateau fractures; Orthopaedics and traumatology: Surgery and Research (2013) 995, 5208-5218

23. G. Copciag et al: the surgical treatment of tibial plateau fractures: Arthroscopy versus arthrotomy. AMT,V.II.No.I,2009,P-168

24. George K. Dendrinos, Savas Kontos, Demetrios Katsenis, Athanasios Dalas: treatment of high-energy tibial plateau fractures by the ilizarov circular fixator.( $\mathrm{J}$ Bone Joint Surg [br] 1996;78-b:710-7)

25. Gregory M. Buchko and Donald H. Johnson: arthroscopy assisted operative management of tibial plateau fractures. Clinical Orthopaedics and Related Research1996; pp 29-36.

26. H.Kiefer, N.Zivaljevic, J.E.Imbriglia. Arthroscopic reduction and internal fixation of lateral tibial plateau fractures. Knee Surg, Sports Tranmatol Arthrosc (2001)9: 167-172)

27. Holzach P et al: Arthroscopically assisted treatment of lateral tibial plateau fractures 
in skiers: use of cannulated reduction system. J Orthop Trauma 1994;8:273-81

28. Honkonen S. Indications for surgical treatment of tibial condylar fractures. Clin Orthop 1994;302:199-205

29. Jain D et al: Results of proximal tibial fractures managed with periarticular locking plates. IJRRMS vol-2 No. 4 OctDec 2012.

30. James H. Lubowitz, Kennan J. Vance, D.O., Mina Ayala, S.T., and Dan Guttmann "interference screw technique for arthroscopic reduction and internal fixation of compression fractures of the tibial plateau." The Journal Of Arthroscopic And Related Surgery, Vol 22, No 12 (December), 2006: pp 13591359)

31. James H.Lubowitz, Wylie S.Elson et al: Arthroscopic management of tibial plateau fractures. The Journal Of Arthroscopic And Related Surgery.2004 ;20 pp: 10631070

32. Jennings JE. Arthroscopic management of tibial plateau fractures. Arthroscopy 1985; $1: 160-8$

33. Jpswalia, Avinash Gupta, Surinder kumar, Sonamkaurwalia, Sargun Singh. Role of tibial buttress plating in fracture of upper end tibia: Pb Journal Of Orthopaedics volXII, no.1, 2011 ;pp 27-30

34. Jong-Keonoh et al: Locking plate in proximal tibial fractures: A correlation between the coronal alignment of tibia and joint screw angle. Yonsei Med J 54(3):720-725,2013

35. Jun Suganuma and Seiji Akutsu: arthroscopically assisted treatment of tibial plateau fractures. The Journal of Arthroscopic And Related Surgery,2004;20:pp-1084-1089

36. Koval, Kenneth J, Polatsch, Daniel; Kummer, Frederick J. Cheng, Deyu; Zuckerman, Joseph D: Split fractures of the lateral tibial plateau, evaluation of three methods. Journal of Orthopaedic Trauma, July 1996 - volume 10 - issue 5 pp 304-308.

37. Lobenhoffer $\mathrm{P}$ et al: Closed reduction/ percutaneous fixation of tibial plateau fracture: Arthroscopic versus fluoroscopic control of reduction. J orthop. Trauma 1999 Aug 13(6):426-31.

38. Mehmet Asik, Ozgur Cetik, Ufuk Talu, Yunus V. Sozen. Arthroscopy-assisted operative management of tibial plateau fractures. Knee Surg, Sports Traumatol, Arthrosc(2002) $10: 364-370$

39. Mark L. Purnell, Andrew I. Larson, Bsme, Kent A: Diagnosis and surgical treatment of schatzker type IV variant biplanar medial tibial plateau fracture. Techniques In Knee Surgery 6(1):17-28, 2007

40. Mohamed Zaki Abdel-Hamid, ChungHsun Chang, Yi-Sheng Chan: Arthroscopic evaluation of soft tissue injuries in tibial plateau fractures: retrospective analysis of 98 cases. The Journal Of Arthroscopic And Related Surgery,2006; vol 22:pp 669-675

41. Neeraj Mahajan et al: Evaluation of results of various operative methods in the management of tibial plateau fractures in adults. JK SCIENCE Vol.11, No.1, January-March 2009.

42. Nicola's Manidakis et al Tibial plateau fracture: Functional out come and incidence of osteoarthritis in 125 cases. International orthopedics(SICOT) 2010 34:505-570

43. Nirmal C Tejwami: Arthroscopic assisted management of tibial plateau fractures. Technique in knee surgery; 2005:4(4):237241

44. N. Lindsay Harris, Mark L, Purnell and Tomas Pevny: Arthroscopic management of tibial plateau fractures. Techniques In Knee Surgery 2007;6:9-16)

45. Ozgur Cetik, Hakan Cift, and Mehmet Asik: Second-look arthroscopy after arthroscopy-assisted treatment of tibial 
plateau fractures. Knee Surg Sports Traumatol Arthrosc (2007) 15:747-752

46. Radheshyam Sament et al: Closed reduction and percutaneous screw fixation for tibial plateau fractures. Journal of orthopaedic surgery 2012;20(1):37-41

47. Rasmussen, P.S.: Tibial condylar fractures. J. Bone and Joint surg., 55A:1331, 1973

48. Richard A. Demon, and David H. Bartlettist. Arthroscopic assisted internal fixation of certain fractures about the knee. The Journal Of Trauma 1985; Vol 25;355358

49. Roberto Rossi, Filippo Castoldi, Davide Blonna: Arthroscopic treatment of lateral tibial plateau fracture, a simple technique. The Journal Of Arthroscopic And Related Surgery,2006; vol. 22:p 678

50. Rockwood and Green's Fractures in adults $7^{\text {th }}$ edition; vol. 2: $1780-1831$

51. Schatzker J.et al. The tibial plateau fractures. Clin Orthop(1979)138:94-104

52. Seppo E, Honkonen Markkuj, Jarvinen: Classification of fractures of tibial condyles. J Bone Joint Surg (1992) 74-b; 840-7

53. St. Cristea et al. The role of Arthroscopy in mini-invasive treatment of tibial plateau fractures. OTSR-RCO-D-11-00169/2011.

54. S.T. Smith, J.L.Marsh and J.V. Nepola: Tibial plateau fractures treated with external fixation and minimal internal fixation. The Lowa Orthopaedics1991: vol. 2 pp 69-77

55. Thomas J. Gill, Darius M.Moezzi, Kenneth M: Arthroscopic reduction and internal fixation of tibial plateau fractures in skiing. Clinical Orthopaedics 2001; 383, pp 243-249
56. T.Ohdera, M.Tokunaga, S.Hiroshima, E.Yoshimoto: Arthroscopic management of tibial plateau fractures; comparison with open reduction method. Arch Orthop Trauma Surg (2003)123:489-493

57. Tomas Pevny, Mark L. Purnell, N. Lindsay Harris and Andrew I. Larson. Arthroscopic fixation of tibial spine fractures. Techniques in Knee Surgery2007; 6, pp 2-8.

58. T. Scheerlinck, C. S. Ng, F. Handelberg, P. P. Casteleyn. Medium-term results of percutaneous, arthroscopically-assisted osteosynthesis of fractures of the tibial plateau. J Bone Joint Surg (br) 1998;80b:959-64

59. Tushar Agarwal et al: Management of closed tibial plateau fractures with percutaneous cancellous screw fixation. Medical Journal of Dr. D.Y Patil university 2013/vol.6/issue-1

60. V.S.Ravindranath et al: A new device for percutaneous elevation of the depressed fractures of tibial condyles. Journal of orthopedic case reports 2012 April-June: 2(2):24-26.

61. Walker PS, Erkman MJ. The role of menisci in force transmission across the knee. Clin-Orthop 1975;109:184-92

62. Yi-Sheng Chan et al: Arthroscopy assisted surgery for tibial plateau fractures. Chang Gung Med j 2011;34:239-47

63. Zahid et al: The role of JESS (Joshi's external stabilization system) fixator in the management of tibial plateau fractures which are associated with severe soft tissue injuries. Journal of clinical and diagnostic research.2010 dec; (4):33563361. 